\title{
PERSPECTIVES OF ORGANIC AGRICULTURE AND POLICY CONCERNS IN NEPAL
}

\author{
Deepak Mani Pokhrel $(\mathrm{PhD})^{1}$ and Kishor Prasad Pant (MSc) ${ }^{2}$
}

\begin{abstract}
Agriculture production worldwide has been intensified with a simultaneous expansion in pesticides, fertilizers and other agro-chemicals use to meet growing peoples' demands for food. Indiscriminate use of agrochemicals has however resulted in several problems such as pests' resistance to pesticides and resurgence due to elimination of natural enemies, toxic residues in food, water, air and soil, degrading soil environment and ecosystem, animal and human health hazards and ultimate economic losses. Realizing the facts, organic farming is becoming popular recently, and there have been growing concerns on its importance and promotion in number of countries irrespective of their stage of development. Consequently, farming system paradigms have now shifted from mere increased production and productivity to resource sustainability and eco-friendly production techniques in their emphasis.
\end{abstract}

Higher cost due to agro-chemicals and resulting environmental losses incurred in conventional agriculture on one side and higher advantages of ecological diversities available in the country on the other have proved that Nepal has high potentialities and comparative advantages of producing quality organic products. A high majority of mountain farmers in Nepal, excluding a few of the agricultural pockets where so-called commercial agriculture has already introduced, do not use any chemicals. Owing to globally increasing trend of demand for organic food, Nepal can benefit from such exports. The government based on some of its policy instruments is also committed to promoting organic farming in the country. However, the instruments are inadequate and not well integrated. Inadequate research, extension services and manpower especially on production and marketing information and input supply have hindered promotion of organic agriculture. Organic product legislation, standardization, certification and infrastructure in such development are also major issues of policy concerns.

Key words: organic-certification, organic-farming, organic-standard, policy, Nepal

\section{BACKGROUND}

The conventional agriculture focused merely on yield rise to meet growing food needs of increasing population, and paid little concerns to sustainable use of locally available both natural and human resources. This resulted in mere intensive use of agro-chemical inputs but a wide productivity gap between the best possible and the farm practice; agricultural lands continued to shrink, and farming system led to environmental degradation such as depletion of soil and soil fertility, decline in water availability and increase in different forms of pollution. At the same time, such practice upset both environmental resources and indigenous knowledge system rendering the agriculture system unsustainable (Scialabba, 2000). Realizing the facts, importance of organic farming is increasing, and the goal of agricultural development in many countries shifted from mere increased production and productivity to achieving sustainable and environment friendly production system.

Organic agriculture is one of several approaches to sustainable agriculture development practiced today, which is ecologically safe, economically viable and socially acceptable

1 S. Hort. Dev. Officer, GEED, MOAC. E-mail: dmpokhrel@moac.gov.np

2 Agri. Ext. Officer, GEED, MOAC. E-mail: kppant@moac.gov.np 
(Scialabba, 1999). As been widely accepted, it is a holistic production management system that emphasizes on the use of management practices accomplished by using agronomic, biological and mechanical methods in preference to off-farm inputs and as opposed to using synthetic materials to fulfill any specific function within the system. Of which, the soil is of central importance, and the primary goal is to optimize the health and productivity of interdependent communities of soil life, plants, animals and human being. Prohibiting the use of genetically modified organisms (GMOs), it avoids or largely excludes the use of chemical pesticides, herbicides, fertilizers, growth regulator, hormones and antibiotics. In several ways, the system can help to promote and enhance healthier agro-ecosystems including biodiversity, biological cycles and soil biological activity. In reality, organic farming is a consistent system approach based on the perception that tomorrow's ecology is more important than today's economy.

Table 1: Pesticides consumption in Nepal (PRMS, 2007)*

\begin{tabular}{l|c|c|c}
\hline \multirow{2}{*}{ Kinds of pesticide } & \multicolumn{3}{|c}{ Quantity (a.i. in kg). } \\
\cline { 2 - 4 } & year 2004 & year 2005 & year 2006 \\
\hline a. Agricultural uses & $\mathbf{1 5 7 9 3 6}$ & $\mathbf{1 4 8 1 7 2}$ & $\mathbf{1 2 8 7 2 8}$ \\
1. Insecticides & 44962 & 65196 & 46553 \\
1.1 Organochlorine (endosulfan) & 2473 & 3097 & 8215 \\
1.2 Organo-phospates (acephate, chlorpyriphos, quinalphos, & 26912 & 25401 & 24683 \\
$\quad$ dichlorovos, phorate) & 191 & 1008 & 115 \\
1.3 Carbamates & 3147 & 31050 & 2640 \\
1.4 Syn. pyrethroids (alpha-, cyper-, deltamethrin, fenvalerate.) & 17 & 4 & 4 \\
1.5 Botanical products (azadiractin) & 1235 & 1147 & 2290 \\
1.6 Mixed insecticide (chlorpyriphos+cyper/alphamethrin & & & \\
$\quad$ +chlorpyriphos, quinalphos+cypermethrin, etc.) & 10988 & 3489 & 8606 \\
1.7 Others (aluminiumphosphide, cartaphydrochloride, & & & \\
$\quad$ imidacloprid, propargite, ethofenprox, fenpropathrin, & 6186 & 11230 & 5702 \\
$\quad$ fipronil etc.) & 102004 & 67699 & 74369 \\
2. Herbicides (glyphosate, 2,4-d, butachlor, etc.) & 1523 & 1457 & 1808 \\
3. Fungicides & 4.3 & 30.4 & 57.6 \\
4. Rodenticides & 864 & 77 & 239 \\
5. Bio-pesticides (bt, npv, etc) & 12.0 & 13.8 & 0 \\
6. Acaricides (dicofol, propargite) & 2380 & 2469 & 0 \\
7. Bactericides & $\mathbf{1 4 0 6}$ & $\mathbf{3 3 0 0}$ & $\mathbf{2 5 5 7}$ \\
8. Others (metaldehydes, chloroflurazuron, etc.) & $\mathbf{1 5 9 3 4 2}$ & $\mathbf{1 5 1 4 7 2}$ & $\mathbf{1 3 1 2 8 5}$ \\
b. Public health uses (alphacypermethrin, lambda cyhalothrin) & Grand total (a+b) & & \\
\hline
\end{tabular}

* Pesticide consumed in any year= Pesticide imported in the year + Stock from the previous year

\section{NATIONAL CONSUMPTION OF FERTILIZERS AND PESTICIDES}

A substantially increasing rate of pesticides consumption in agricultural use would be expected over the past decades (PPD, 2007) despite a decreasing trend in the recent year (Table 1). However, average consumption is very low as compared to other countries (Palikhe, 2002). According to PPD (2007), annual consumption of pesticide in Nepal was 131.3 Mt of a.i. formulations (valued NRs. 131284500) in 2006. Organophosphates, carbamates, selective and pre-emergence herbicides (including atrazine and its urea substitutes) and systematic and dicarbamate-based fungicides are the major types of pesticides commonly used. Of the total pesticide consumption, about $40-50 \%$ is used in rice, $10-20 \%$ in vegetables and the rest in cash 
crops. An increase in consumption of pesticides in the country is also attributed to increasing area under seasonal and off-season vegetables.

Fertilizer is one of the prioritized inputs of agricultural production; the import of which in the country increased significantly after the implementation of Fertilizer Deregulation Policy 1997 and National Fertilizer Policy 2002. However, total consumption has been far below the level as envisaged by Agriculture perspective Plan (NPC, 1995).

Average fertilizer consumption in Nepal is $26 \mathrm{~kg} / \mathrm{ha}$ as of 2002 (SAIC, 2004), which is very low as compared to other SAARC countries, where the consumption is $166 \mathrm{~kg} / \mathrm{ha}$ in Bangladesh, $197 \mathrm{~kg} / \mathrm{ha}$ in India, $136 \mathrm{~kg} / \mathrm{ha}$ in Pakistan and $277 \mathrm{~kg} / \mathrm{ha}$ in Sri Lanka (SAIC, 2004). But unbalanced use of fertilizers is widespread in the country specifically in areas where commercial production of crops has already started.

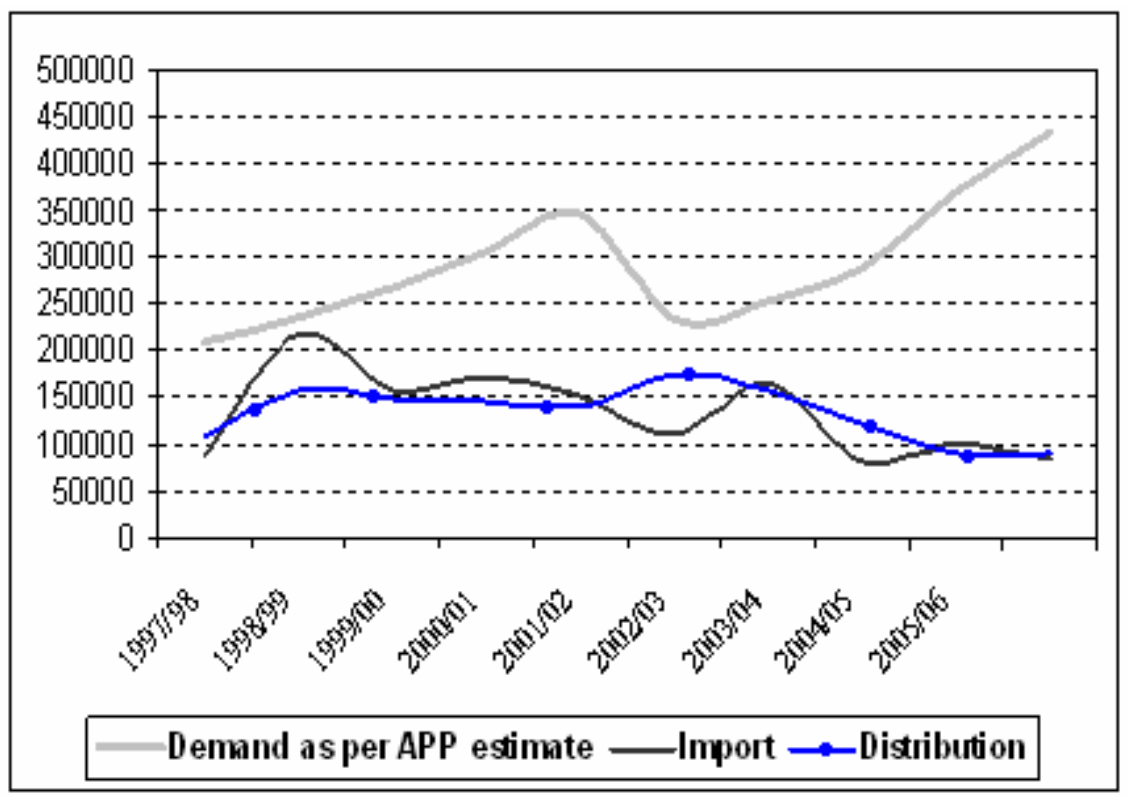

Figure1: Demand, import and distribution of fertilizer after fertilizer deregulation in $\mathrm{Mt}$ (MOAC, 2007).

\section{IMPORTANCE OF ORGANIC AGRICULTURE}

Agriculture is one of the major contributing sectors in Nepalese economy that shares $36 \%$ in the GDP at 1984/85 constant price (MOAC, 2007) and provides employments to two-third of the economically active population (MOAC, 2006). The government, through the past development plans, has made significant efforts to increase agricultural production and productivity. However, the efforts have not yielded results to desired levels due mainly to difficult topography, poor infrastructural development and high level of farm poverty (NPC, 2007).

Nepalese agriculture is predominately characterized by traditional knowledge based subsistence type with low productivity. The agricultural systems in the mountain comprise $2 / 3^{\text {rd }}$ of the nation's geographical area and largely integrate crops and livestock to traditional knowledge and locally available resources. With very low productivity, the systems are largely 
organic by default for maintaining soil fertility and production. Most of the farmers in the high mountain and majority of them in the middle mountain do not use chemical inputs in their farming. The use of agro-chemicals such as fertilizers and pesticides is becoming important only to the commercial agriculture pockets recently being developed in the accessible areas. With introduction of improved agronomic and composting practices, biofertilizers and bio-pesticides, there is greater possibility of converting the systems to organic types with little effort. Farmers in the terai are producing crops in combination of both indigenous and conventional knowledge system. Organic farming with low productivity is adopted in a few areas (Pant, 2006).

In Nepal, use of pesticides and fertilizers is wide spread in commercial production areas due to conventional agriculture based market and infrastructure development. Pesticides and fertilizers consumption is increasing at faster rate with intensification of farming business regardless of their detrimental effects on human and environmental health. Indiscriminate use of the agro-chemicals has, in consequence, initiated several problems such as pests' resistance to pesticides and resurgence due to elimination of their natural enemies, environmental pollution (water, air, and soil), toxic residues in food and feed materials, depletion of soil fertility, disruption of ecosystem, animal and human health hazards and other economic losses. This forces to think alternative strategies towards sustainable agriculture development and preserving natural eco-system.

\section{PRESENT STATUS OF ORGANIC AGRICULTURE DEVELOPMENT}

Though sounds as a new terminology, 'organic farming' is not a new concept in Nepalese context, where a very high percentage of agriculture farming is by default organic in nature. This is a good prospect of organic farming development in Nepal. Over a century, dominantly resource poor and subsistent farmers are practicing organic farming in traditional way. As a common phenomenon in Nepalese agriculture system, every farm family keeps a few pair of goats and chickens, a pair of bullock, one or two cows or buffaloes integrated with crop farming. Despite a prevailing argument that whether such farming can be called an organic or indigenous knowledge based, transforming the system to organic is not difficult in Nepal. Moreover, such a development would be conducive to poverty alleviation in the country.

So far establishment of commercial organic farming in Nepal was started in the early 1990s. Though organic farming accounts for small segments in terms of both acreage and production, it is gaining momentum for its ecological importance and economical opportunities. Recently, there have been growing interests from both government and non-government sectors at different levels for its promotion, and farmers have been growing different organic crops individually or collectively. The common practices adopted by the organic growers are crop rotation, natural pest management and using bio-fertilizers and organic manures mainly farmyard manure, vermi-compost and green manure in soil fertility management. The major organic products grown in Nepal and available in the market are tea, coffee, large cardamom, ginger, fresh-vegetables, honey and herbal products. However, data related to area coverage, production, certification procedures and market situation of the commodities are extremely limited. As reported by International Federation of Organic Farming Movement (2006), the number of organic farms in Nepal is 1247, and the area under organic management is 1000 ha. If the area under traditional farming where farmers never used fertilizers and pesticides is considered, the area under organic farming should be much higher. 


\section{ORGANIC AGRICULTURE DEVELOPMENT INITIATIVES}

Some initiatives have been taken by government (such as DOA, NAST, NARC, IAAS, Tea and Coffee Development Board, Kathmandu Metropolitan), non-government (I/NGOs such as SSMP, Winrock International, ECOCENTER, Nepal Permaculture Group, SECARD, HOPTA and AEC) and community-based organizations to promote organic farming in the country. Despite that level of organic technology generation and dissemination is not much significant. Extension services provided by government agencies are very limited, and are confined to awareness raising and training programs. Institutional supports promoting organic farming are also limited. Professional institutions are not functionally established to assist farmers in the production, post-production, product certification and marketing processes. NGOs and private service providers are catering the technological need of organic farmers to some extent. They have played a major role in supporting farmers' associations in their program areas in adopting organic methods of crop production and inspection, and product certification and marketing.

\section{POLICIES AND STRATEGIES ON ORGANIC AGRICULTURE DEVELOPMENT}

As the relationship between agriculture and environment has been recognized, some policy statements to reduce detrimental effects of agriculture on environment have been undertaken ever since the seventh plan. In this regard, the state has enacted Plant Protection Act 2048, Pesticides Act 2049 and Regulation 2050, Food Act 2023, Consumers' Right Act 2054 and Regulation 2056 and Environment Protection Act 2053 and Regulation 2054 and formulated National Standards of Organic Agriculture Production and Processing 2064 and some other relevant policies and strategies though fragmented and inadequate. The state is yet to formulate some effective policies including laws and regulations regarding production and trade of organic agricultural products.

Till date, the Agriculture Perspective Plan (1994/95--2017/18) has been considered as a guiding strategy towards agricultural development in the country (NPC, 1995; NPC, 1997) that aims at achieving increased agricultural economic growth through priorities on intensive use of limited inputs essentially non-organic. Moreover, the APP strategies are considered as guiding principles in the succeeding periodic plans, policies and strategies (NPC, 1998: NPC, 2003; MOAC, 2004; NPC, 2007), which are developed in line with the APP objectives. The plan is basically apathetic to organic development of agriculture since harnessing comparative advantages of available resources through organic agricultural products is not possible under existing system of indiscriminate markets for organic and inorganic products in the country.

The 10th Plan (NPC, 2003) and National Agricultural Policy (MOAC, 2004) have, for the first time, spelt out policy statements regarding promotion of organic farming in the country. The policy documents have adopted one of their objectives as to conserve, promote and utilize natural resources, environment and biodiversity, which vaguely infers to a kind of state emphasis laid on development of organic agriculture. The Agriculture Policy, 2004 has policy statements for encouraging organic farming, supporting organic products certification, minimizing adverse effects of agrochemicals in livestock products, land, water and other aspects of environment, improving production and usage of organic manure, enhancing local participation in food quality management and regulating use of pesticides and GMO. In addition, the then and succeeding periodic plans emphasize on promoting integrated plant nutrients and pest management (NPC, 2002: NPC, 2007). Three Years' Interim Plan (NPC, 2007) has a mention that farms' increasing dependence on pesticides and their improper and indiscriminate use on crops had adverse effects on environment and human health. And the 
plan, on a broad basis, has laid emphasis on developing and disseminating eco-friendly technologies, developing such technologies on indigenous knowledge and skills and protecting farmers' rights on such knowledge system. Agribusiness Promotion Policy 2006 has a policy statement for the development of special production zones including organic/pesticide free production area though a clear strategy towards implementing the policy is yet to be established.

Based on state policy, fertilizer constitutes a key component for achieving increased agricultural production through improving soil fertility, which is not the only remedy sufficient to replenish the crop removals from soil. Therefore, the preamble of the National Fertilizer Policy, 2002 has emphasized balanced use of fertilizers, adoption of Integrated Plant Nutrients system (IPNS) and promotion of organic and microbial fertilizer use in order to prevent degradation of soil fertility and other likely negative impacts of fertilizers on environment. Previously the policy had no provision for direct subsidy on fertilizers excepting that on transportation for some inaccessible areas. Recent amendment (2065) has introduced direct subsidy on price to enhance fertilizer consumption in the country. The state has been allocating huge amount of money each year for subsidy on fertilizer transport. A wide gap observed between the budgetary allocation and the expenditure indicates towards low productivity of scarcely available resources (Figure 2). Transfer of that to organic agriculture development especially in inaccessible areas would be much rational.

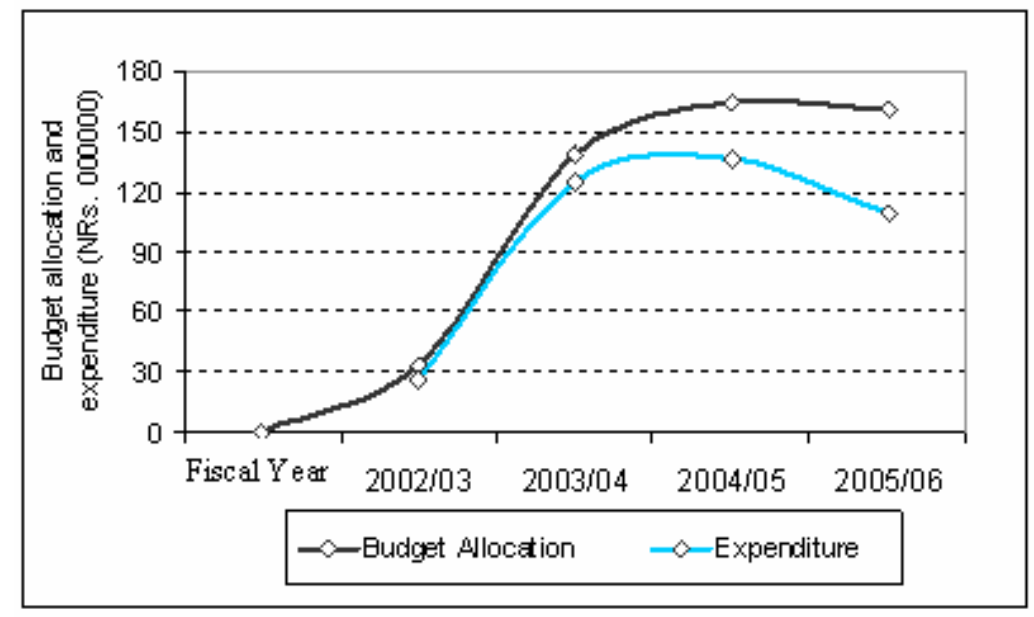

Figure 2: State provision of subsidies on fertilizer transportation (DOA, 2006)

\section{PROGRAMS IN SUPPORT OF ORGANIC AGRICULTURE DEVELOPMENT}

Realizing vital role of plant protection in sustainable agriculture, Agriculture Prospective Plan as well as succeeding periodic plans have endorsed Integrated Pest Management (IPM) as a new extension approach to solve pest and pesticide problems. The IPM program introduced farmers' field school as effective tools of extension teaching, which emerged as a pioneer approach to address farmers' problems through community participation (PPD, 2003). More than 15,000 farmers including 4,500 women have been trained through 600 FFS throughout the country (PPD, 2007). As a result, a reduction in pesticide consumption by $55 \%$ and an increment in crop production by $10 \%$ are reported (PPD, 2005). 
Sustainable Soil Management Project (SSMP) is also launching several activities in favor of organic agriculture particularly in areas of soil fertility management and organic coffee production.

\section{ORGANIC AGRICULTURE STANDARDS AND PRODUCT CERTIFICATION}

The certification of organic products has not been gaining momentum in Nepal though it was introduced in 1996 (Vaidya, 2006). In the national level, the norms and standards required for production, inspection and certification of organic products have not yet been implemented except some initiatives taken by some private traders and NGOs. Some internationally recognized certifying agencies such as National Association of Sustainable Agriculture Australia (NASAA), the Institute for Marketecology (IMO, Switzerland), the Ethical and Environmental Certification Institute (ICEA, Italy), Ecocert France, OneCert America and Organic Certification Nepal show their local presence to work on organic product certification. With the implementation of National Standards of Organic Agriculture Production and Processing 2007 (2064) the organic certifiers operating in the country are to be accredited and regulated by National Accreditation Body, which is yet to be operated.

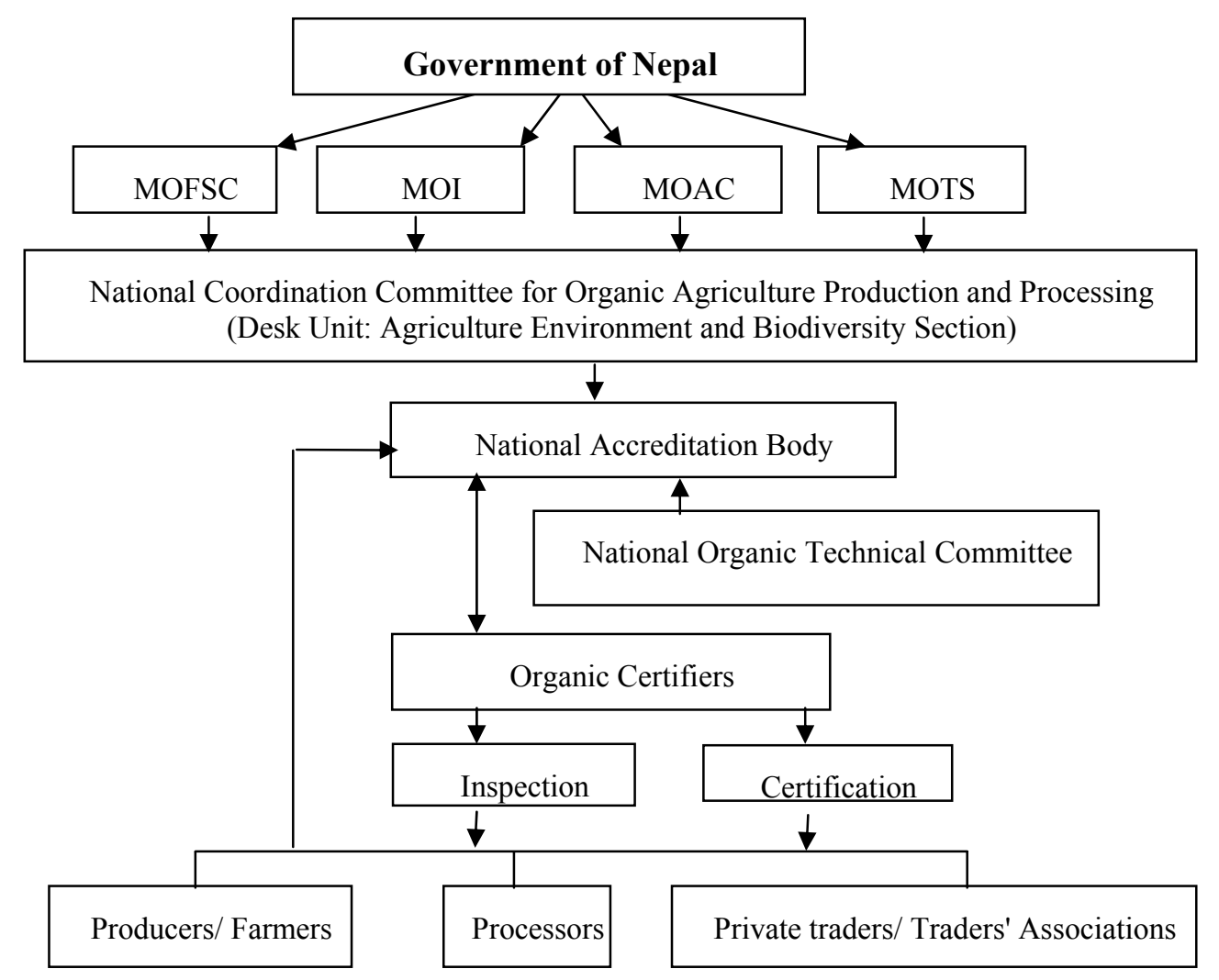

Figure 3: Structural arrangements for Organic certification

In compliance with IFOAM and CAC guidelines, the National Standards of Organic Agriculture Production and Processing 2007

- specifies land arrangement for organic production, 
- prohibits agro-chemicals contamination in crop production and product transfer and storage, use of inorganic feeds, GMOs/LMOs and radioactive devices and burning of organic wastes,

- limits use of fertilizers, undecomposed and poultry manure and town-compost,

- emphasizes using local-variety, organic seed source and no chemical seed treatment technique,

- avoids torturous raring of animals, fetal implantation, cloning and hormonal use in animal production

- limits artificial insemination in livestock as well as fish production

- protects farmers for fair remuneration from their produces, and employees, children, consumers and tribal groups for their rights

- provides structural arrangements for organic certification and

- recognizes private sectors as key stakeholders in designing policies and organic certification.

\section{MAJOR CHALLENGING ISSUES}

There is no doubt that organic agriculture is more sustainable and low input based farming system. But, there are several challenging issues to be resolved both on theoretical and practical grounds for promoting organic farming in Nepal. In order to make national product competitive in the domestic and international market, the country has many problems and constraints to face. The major being setting up own norms and standards for individual products, developing product guarantee and certification mechanism and awareness building to state agencies, organic producers, traders, consumers and other stakeholders. Certification process itself is more complicated and costly that smallholder Nepalese farmers hardly can afford the costs. In addition, plant nutrients supplied by organic manure may be costlier than that from fertilizers (pant, 2006). The relative cost of organic production is generally higher and the prices available compared to non-organic products are relatively low, which is not fair to organic producers. Meeting harsh norms and standards through continuous supervision of the production, transfer and storage and laboratory tests of the products also add to the cost of organic farming. Moreover, food safety, hygiene and sanitation are very important for organic products. It requires good agricultural practices, standard procedure and quality assurance system (services) through accredited institutions. In Nepal, such institutions are very limited in both government and private sectors. Quality assurance, reliable marketing information and other services and rules/regulations complying with those of importing countries are prerequisites to get access in international market. Since the country has least developed institutional framework and infrastructures required for organic agriculture, it is a challenging issue to bring the products at international market. Besides, extension personnel in the country have rarely received adequate training in organic farming, and professional institutions dealing with capacity building in organic farming are not functional yet. Risks involved in shifting to new farming methods, uncertainty of crop yields, inability to achieve economies of scale, limited market information, difficult market access and high costs of supervision and certification services are some other challenges in organic agriculture promotion. Additionally, subsidies on imported inputs and no price discrimination between organic and in-organic products are some of the lacuna to upset organic production and processing. Promotion of group certification as well as marketing mechanism would be an 
appropriate solution in response to the above mentioned problems and challenges that calls for deliberate contemplation by state policy makers and organic agriculture promoters.

\section{PROSPECTS OF ORGANIC FARMING AND POLICY GAPS}

Policy instruments associated with organic agriculture development in the country are much fragmented. Integrating them in organic production promotion and trading on such products is much crucial in achieving sustainable agriculture and higher economic growth. The state for dealing in the aforementioned challenges should have

- a clear organic agriculture development policy specifying the roles of government as well as various private sectors. It should have identification of the areas and commodities for organic promotion. State supports including subsidies would be justifiable to reach the organic farmers on the ground of environmental costs.

- Implementation of organic standards and certification programs. Since organic certification is more a 'process' than 'product' certification, the role of certifying agencies is more crucial. In this context, Nepalese standard should be developed focused on the specialty of traditional agriculture practices.

- Commodity specific and location specific organic production zones should be demarcated which will encourage to the producers and ensure marketing mechanisms.

- Residue analysis laboratories and price discrimination systems should be initiated which ensures the trust on the part of the products and likely chances of their "rejection".

- Institutional and legislative arrangement. Establishment and operation of institutions such as National Accreditation Body maintaining and enforcing organic standards and organic certifiers as per the National Standards of Organic Agriculture Production and Processing are vital. Their activities and roles as well as production and marketing mechanism should be guided and regulated by enacting suitable laws. For quality assurance, the production, marketing, storage and transfer including processing of organic agricultural products should come into the purview of domestic laws. Establishment of such institution helps to comply with the international regulations on organic production and trade

- An identification of the priority programs to be implemented including research, development, coordination and capacity building. Viewing limited research on organic agriculture and few of that confined on soil fertility management studies only, adequate priority and resources should be allotted on quality assurance, verifying economic aspects of organic farming and scientific validation of indigenous knowledge and farming practices. Building capacity of extension service providers as well as that of producers and sellers through trainings is important. They should be made well aware of national organic standards, legislation and quality assurance system. Effective extension programs for educating consumers and producers about health, environment and social benefits of organic farming, promotion and documentation of indigenous knowledge and skill, cooperative development and group mobilization and provision of information regarding market opportunities (demand/supply), price premiums and consumers' preferences are also essential. For such implementation, an effective linkage and coordination among 
government and private participants is crucial. Explicit policies, norms and standards and clarity in enforcement of legislation would bring them into strong linkage.

\section{CONCLUSION}

Over a century, especially resources-poor and subsistent Nepalese farmers are dominantly practicing organic agriculture to which, due to increasing demands for organic produces, domestic as well as export markets are visible for their livelihood improvement. On such ground, the state, through its policies and periodic plans, has emphasized promotion of organic agriculture. However, the country is not committed to such endeavors since some important policies, laws and regulations regarding production and trade of organic agricultural products are yet to be formulated and agriculture development programs streamlined to such achievements.

Formulation of National Standards of Organic Agriculture Production and Processing (2064) has been an important step, which has left doors open to organic producers, promoters and certifiers to contribute to organic production and processing promotion. However, implementing the standards is itself a major challenge as setting standards, making people aware of them, meeting them at various stages and certification mechanisms for individual products are complicated and costly. Besides, policy instruments associated with organic agriculture development in the country are observed much fragmented and, sometimes, conflicting. For example, subsidies on imported inputs such as fertilizers and no discrimination of prices for organic and inorganic produces are not conducive to such promotion. Integrating policies in organic production promotion and trading is crucial and, for such achievement, a clear organic agriculture development policy, implementation of organic standards and certification programs, demarcated organic production zones, organic-inorganic price discrimination, necessary institutional arrangements and identification of priority activities are important.

\section{REFERENCES}

DOA, 2006. Progress report 2063/64. Monitoring and Evaluation Section, Department of Agriculture.

MOAC, 2004. National Agricultural Policy, 2061 (Nepali). Kathmandu: Ministry of Agriculture and Cooperative.

MOAC, 2006. Statistical Information on Nepalese Agriculture 2005/06. Kathmandu: Ministry of Agriculture and Cooperative.

MOAC, 2007. Statistical Information on Nepalese Agriculture 2006/07. Kathmandu: Ministry of Agriculture and Cooperative (APSD).

NPC, 1995. Nepal Agriculture Perspective Plan. Nepal: National Planning Commission and Asian Development Bank TA No. 1854-Nep.

NPC, 1997. Nepal Interim Agriculture Perspective Plan. Nepal: National Planning Commission and Asian Development Bank, TA No 2618-Nep.

NPC, 1998. The Ninth Plan. Nepal: National Planning Commission.

NPC, 2003. The Tenth plan. Nepal: National Planning Commission.

NPC, 2007. The Three Years Interim Plan 2064/65 - 2066/67. Nepal: National Planning Commission.

Palikhe, B.R., 2002. Pesticide and environment. Kathmandu: Ministry of Agriculture and Cooperative. 
Pant, K. P., 2006. Organic Agriculture for Sustainable Development in Nepal Paper presented in APO seminar on organic farming for sustainable development held in Colombo, 11-15 Sept, 2006.

PPD, 2003. Integrated pest management through farmer field schools. Proceedings of a workshop organized by National IPM Program in Cooperation with the FAO Program for Community IPM in Asia and Plant Protection Directorate in Kathmandu, 25-26 July 2002.

PPD, 2005. Annual progress report. Plant Protection Directorate. Harihar Bhawan, Lalitpur, Nepal.

PPD, 2007. Annual progress report. Plant Protection Directorate. Harihar Bhawan, Lalitpur, Nepal.

PRMS, 2007. Annual progress report. Pesticide Registration and Management Section, Plant Protection Directorate. Harihar Bhawan, Lalitpur, Nepal.

SAIC, 2004. Statistical Bulletin SAARC Agriculture Data 2004. SAARC Agriculture Information Center, Bangladesh.

Scialabba, N., 1999. Organic agriculture: the challenges of sustaining Food production while enhancing bio-diversity. Rome: FAO. Available at ftp://ftp.fao.org/ docrep/fao/005/ad090e/ad090e00.pdf (April 19,2009).

Scialabba, N., 2000. opportunities and constraints of organic agriculture, A Sociological analysis. Rome: FAO. Available at http:// www.fao.org/ organicag (May 20, 2008).

Vaidya, B., 2006. The organic Scanario in Nepal, Paper presented in APO seminar on organic farming for sustainable development held in Colombo, Sir Lanka, 11-15 Sept, 2006.

Yussefi M., 2006. Organic Farming Worldwide 2006 Overview and Main Statistics. In: The World of Organic Agriculture Statistics and Emerging Trends 2006. International Federation of Organic Agriculture Movements (IFOAM). Avialble at: http://orgprints. org/5161/01/yussefi-2006overview.pdf (January 10, 2009). 